\title{
Decreased emission of nitrous oxide from delivery wards - case study in Sweden
}

\author{
Mats Ek • Kåre Tjus
}

Received: 1 March 2007 /Accepted: 19 February 2008 /

Published online: 14 March 2008

(C) The Author(s) 2008

\begin{abstract}
The very potent greenhouse gas nitrous oxide $\left(\mathrm{N}_{2} \mathrm{O}\right)$ is widely used as a mild anaesthetic for mothers in delivery work in Sweden. As a part of the Stockholm County Council environmental program it was decided in 2002 that the emissions should be drastically reduced. Different ways were theoretically evaluated, and catalytic splitting to nitrogen and oxygen gas $\left(\mathrm{N}_{2}\right.$ and $\left.\mathrm{O}_{2}\right)$ was chosen for a demonstration installation. A Japanese commercial unit for treatment of mixed anaesthetic gases (Anesclean ${ }^{\circledR}$ from Showa Denko K.K.) was thoroughly modified and installed at the Karolinska University Hospital at Huddinge in Stockholm in 2004. The destruction of $\mathrm{N}_{2} \mathrm{O}$ was optimised and studied for 2 years. Data from both collection and destruction are given in the article. Of the collected $\mathrm{N}_{2} \mathrm{O}$ more than $95 \%$ was split to $\mathrm{N}_{2}$ and $\mathrm{O}_{2}$ in the very stable system. The overall emission decrease was mainly dependent on the share that could be collected in the specific exhaustion system as compared to the normal room ventilation. Life cycle assessment (LCA) and life cycle costing (LCC) were used to evaluate the actual environmental value and economical cost for the process. Important factors are pointed out.
\end{abstract}

Keywords Nitrous oxide - Laughing gas · Greenhouse gas · Global warming potential · Catalytic splitting $\cdot$ Destruction $\cdot$ Decreased emission $\cdot$ Anaesthetic $\cdot$ Child delivery $\cdot$ LCA

\section{Background}

Nitrous oxide (laughing gas, $\mathrm{N}_{2} \mathrm{O}$ ) is widely used as mild anaesthetic or pain release in Swedish hospitals in connection to child delivery. It is by many anaesthetics considered to be positive since it can be administrated by the mother herself just during periods of severe pain, it is cheap, and it is without known side effects for the mothers and children (Olofsson and Irestedt 1998). However, there might be two drawbacks. Since long time exposure is not healthy (the $8 \mathrm{~h}$ limit value in Sweden is $100 \mathrm{ppm}$ ), it can be an 
occupational health problem if the gas is not properly collected and disposed of when it is breathed out. This is normally done with a separate exhaust system coupled to the administration mask.

The other problem is that $\mathrm{N}_{2} \mathrm{O}$ is a very strong greenhouse gas, about 300 times more effective than the same amount of carbon dioxide $\left(\mathrm{CO}_{2}\right)$. Since $\mathrm{N}_{2} \mathrm{O}$ is inert in the patient/ mother, all used gas will finally end up in the atmosphere, either via special exhaustion or the regular ventilation. In 2001 Stockholm County Council (SCC) used about 40 tons of $\mathrm{N}_{2} \mathrm{O}$ (equivalent to about 12,000 tons of $\mathrm{CO}_{2}$ ), mainly in the delivery wards in their hospitals. It is normally used as a mix of $70 \% \mathrm{~N}_{2} \mathrm{O}$ and $30 \% \mathrm{O}_{2}$. In $2002 \mathrm{SCC}$ set up a goal to decrease the emissions by half from 2001 to 2006, and to have a first installation for $\mathrm{N}_{2} \mathrm{O}$ destruction before the end of 2004. IVL Swedish Environmental Research Institute (IVL) got the task to suggest methods to reach these goals.

In principle $\mathrm{N}_{2} \mathrm{O}$ can be either oxidised to $\mathrm{NO}_{X}(X>0.5)$, reduced to $\mathrm{N}_{2}$ with a substance that is oxidised, or split into $\mathrm{N}_{2}$ and $\mathrm{O}_{2}$. Oxidation can be done with a catalyst or with normal thermal incineration. In both cases the result will be $\mathrm{NO}_{X}$, which is also negative from an environmental point of view. Catalytic reduction of $\mathrm{N}_{2} \mathrm{O}$ is widely investigated with different reducing agents; see i.e. Burch et al. (2002), Chaki et al. (2003) and Zhu et al. (2000). Normally insignificant amounts of $\mathrm{CO}_{2}$ are formed from the reducing agent, but this can be completely avoided by using hydrogen gas (Arenas-Alatorre et al. 2005).

Splitting into $\mathrm{N}_{2}$ and $\mathrm{O}_{2}$ can be done with different catalysts and at different temperatures; se i.e. Liu et al. (2005). No real comparison between methods was made by IVL for SCC, since a reference to a commercially available unit to destroy $\mathrm{N}_{2} \mathrm{O}$ and separate other anaesthetic gases from hospitals was found (Kai et al. 2002). Since this was the only reported similar system, and the first destruction system had to be installed soon the work concentrated on modification of this unit.

\section{Description of the system}

\subsection{The catalytic splitting unit}

The existing commercial unit, called Anesclean ${ }^{\circledR}$, is used to treat total anaesthetic gas mixtures from surgery in Japan hospitals. Other gases than $\mathrm{N}_{2} \mathrm{O}$ are adsorbed in columns as a first step. The second step is the splitting of $\mathrm{N}_{2} \mathrm{O}$ in a heated catalyst bed (mainly $5 \%$ rhodium on $\mathrm{Al}_{2} \mathrm{O}_{3}$ ). There are two columns for adsorption, while one is adsorbing the other is desorbed and the concentrated gases are condensed by cooling. Less than $1 \mathrm{ppm}$ of these gases remains after adsorption, this is important to protect the catalyst in the second step. $\mathrm{N}_{2} \mathrm{O}$ concentration in this pre-treated air stream can be between 1 and $10 \%$, and the volumetric capacity is $150 \mathrm{~L} / \mathrm{min}$. More than $99.5 \%$ of $\mathrm{N}_{2} \mathrm{O}$ is split to $\mathrm{N}_{2}$ and $\mathrm{O}_{2}$.

A unit to treat the concentrated $\mathrm{N}_{2} \mathrm{O}$ exhaust from all delivery rooms in Karolinska University Hospital at Huddinge would have completely other conditions. No other anaesthetics are present, the air flow varies between 1,000 and 4,000 L/min and the $\mathrm{N}_{2} \mathrm{O}$ concentration between 0 and $10,000 \mathrm{ppm}(0-1 \%)$. After showing in laboratory tests that the catalyst could work at high air velocities and low concentrations without giving other nitrogen containing gases, Showa Denko designed a new unit called Anesclean-SW. This was without the adsorbing step, but had a bigger catalytic bed and especially an effective heat exchange system for the high air flow. The target removal efficiency of $\mathrm{N}_{2} \mathrm{O}$ was set to at least $85 \%$ by SCC, since higher removal efficiency was thought to require too much energy. The system that was finally installed is presented in Fig. 1. 
Fig. 1 Principle of the AnescleanSW collecting system. 1 Connection to existing $\mathrm{N}_{2} \mathrm{O}, 2$ inlet $\mathrm{N}_{2} \mathrm{O}$ gas meter, 3 particle filter, 4 fan that determines the capacity, 5 gas flow meter, 6 heat exchanger, 7 heated catalyst for splitting, 8 outlet $\mathrm{N}_{2} \mathrm{O}$ gas meter, 9 fan to dilute and cool treated air

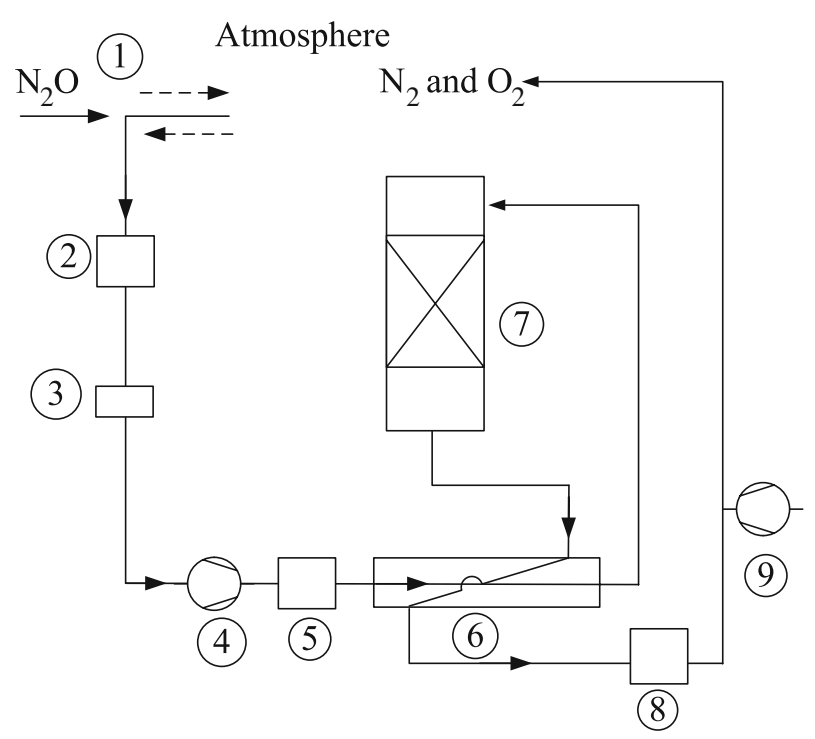

2.2 The gas collection and exhaust system

Karolinska Huddinge hospital already had a separate exhaust system from the masks providing $\mathrm{N}_{2} \mathrm{O}$ to the mothers. The system called Anevac was installed by Medicvent $\mathrm{AB}$, a Swedish medical technology company. Each double-mask both provides a mixture of $\mathrm{N}_{2} \mathrm{O}$ and $\mathrm{O}_{2}$, and collects the exhaust air via a separate line. The gas flow starts when a mother grabs the mask and starts to breathe in it. A central fan maintains a certain negative pressure in the system for all 11 delivery rooms. This gives a relatively efficient collection of the exhaust air from the mother. The base gas flow is about $1,000 \mathrm{~L} / \mathrm{min}$, and it increases by about $400 \mathrm{~L} / \mathrm{min}$ for each mask that is used. In practice, the total air flow is very seldom over $3,000 \mathrm{~L} / \mathrm{min}$. The concentration increases with the flow rate, when there are more deliveries at the same time.

Both Anesclean-SW and Anevac have their own fans, and they have to be connected. This was done according to Fig. 2.

The flow rate into Anesclean-SW is set to a chosen value. When the flow rate from Anevac and the delivery rooms is lower than this, some air from outside the building is taken into the Anesclean-SW. When the flow rate is higher (a small portion of the time according to flow rate measurements and as shown in Fig. 6) some of the $\mathrm{N}_{2} \mathrm{O}$ contaminated air goes outside the building, over the roof (compare 1 in Fig. 1).

\section{Optimisation of the system}

After the installation guarantee period with the suppliers running parameters, airflow and temperature in the catalyst were varied in a factorial experiment in the spring 2005 (Ek et al. 2005). Each set of parameters were fixed for 1 week, to decrease the influence of different amounts of births. During this period a total amount of $470 \mathrm{~kg} \mathrm{~N}_{2} \mathrm{O}$ was treated by the Anesclean-SW system. The average concentration before treatment was $650 \mathrm{ppm} . \mathrm{N}_{2} \mathrm{O}$ was only used during approximately $50 \%$ of time, the average $\mathrm{N}_{2} \mathrm{O}$ concentration during 
Fig. 2 The connection between Anevac and Anesclean-SW

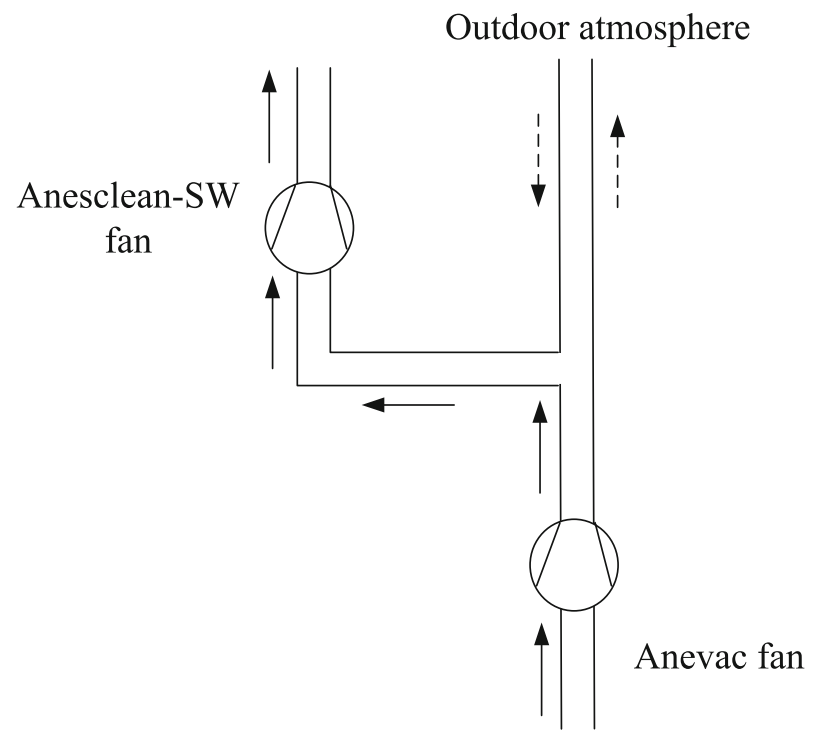

the active time was $1,370 \mathrm{ppm}$. Figure 3 shows the reduction of $\mathrm{N}_{2} \mathrm{O}$ concentration as a function of temperature and air flow according to the developed model.

Unfortunately, the most interesting flow rate was slightly outside the flow ranges used in the experiment, but no discontinuity was expected in the range 2.3 to $2.5 \mathrm{~m}^{3} / \mathrm{min}$. A higher temperature up to at least $400^{\circ} \mathrm{C}$ was positive under normal conditions. The splitting efficiency increased slightly with lower air flow rate, due to a longer retention time in the catalyst.

Fig. 3 Percent reduction of $\mathrm{N}_{2} \mathrm{O}$ concentration as a function of temperature and air flow

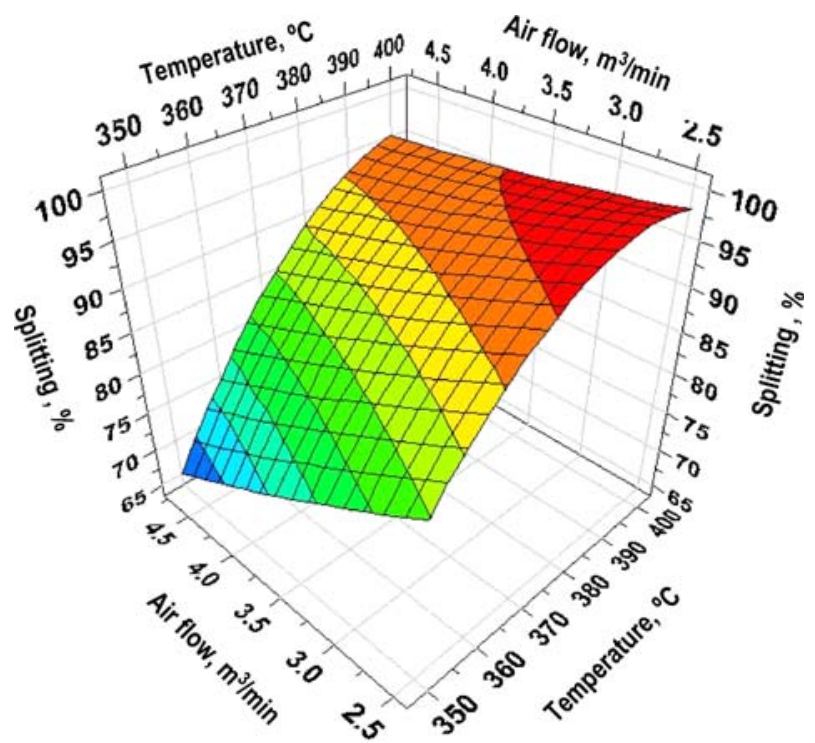


Fig. 4 Effect demand as a function of temperature and air flow

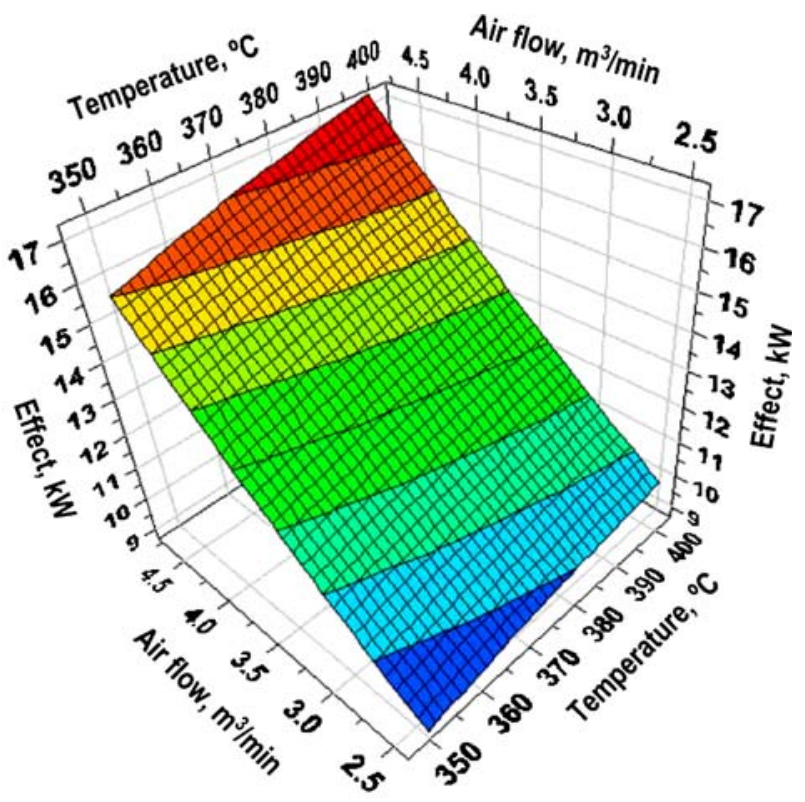

However, the amount of electric energy to run the fan and especially to heat the catalyst to the chosen temperature increased fast with increasing air flow and a little with increasing temperature, Fig. 4.

Figure 5 shows the specific energy demand per amount of destroyed $\mathrm{N}_{2} \mathrm{O}$. Due to the higher splitting rate at higher temperature the specific energy demand decreased with higher temperature. The specific energy demand also decreased with decreasing air flow, mainly

Fig. 5 Specific energy demand as a function of temperature and air flow

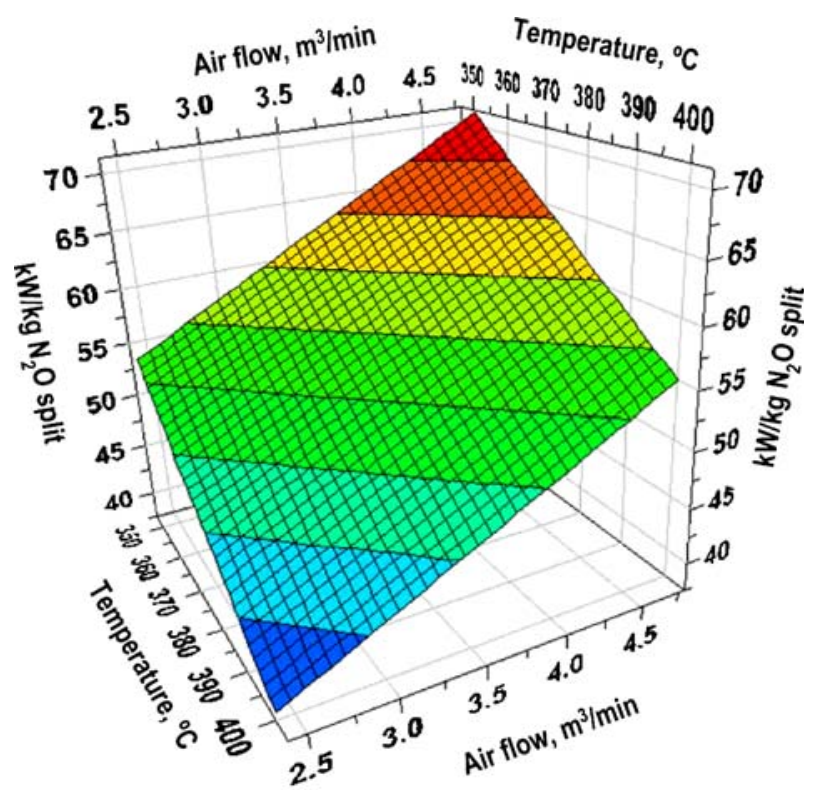


Fig. 6 Percent of $\mathrm{N}_{2} \mathrm{O}$ in the exhaust air that is destroyed, and energy demand per kilogram $\mathrm{N}_{2} \mathrm{O}$ destroyed as a function of flow rate at $400^{\circ} \mathrm{C}$

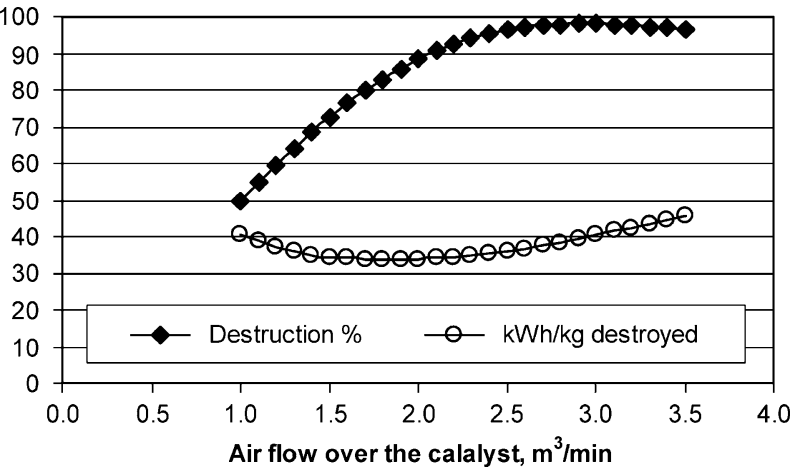

due to less cooling of the catalyst. These specific relationships are of course only valid for the conditions at Karolinska Huddinge hospital.

The practical limits here are the amount of air that has to be treated from the delivery ward, and the working temperature of the catalyst. The catalyst can probably be run continuously at $450^{\circ} \mathrm{C}$, but the lifetime will decrease.

For a total optimisation in this case with varying flow and concentration from the Anevac system a further optimisation of the total system has to be done. A low flow rate through the Anesclean-SW means that more of the contaminated air will be emitted without treatment. Destruction rate and specific energy demand based upon total flow rates and concentrations during the spring 2005 are shown in Fig. 6.

At too low air flow through the Anesclean-SW splitting of $\mathrm{N}_{2} \mathrm{O}$ is complete, but a great part of the $\mathrm{N}_{2} \mathrm{O}$ used in the delivery wards and collected by the Anevac system is lost to the atmosphere, as shown in Fig. 2. At air flow rates over $2 \mathrm{~m}^{3} / \mathrm{min}$ enough of the $\mathrm{N}_{2} \mathrm{O}$ is led to the Anesclean-SW to get an overall destruction over $85 \%$. Based upon this the catalyst temperature was set to $400^{\circ} \mathrm{C}$ and the flow rate in the Anesclean-SW was set to $2300 \mathrm{~L} / \mathrm{min}\left(2.3 \mathrm{~m}^{3} / \mathrm{min}\right)$ for longer evaluation. Measurements of the outlet flow from Anevac showed that in average $95 \%$ of the collected $\mathrm{N}_{2} \mathrm{O}$ will be treated by the AnescleanSW at this air flow rate.

\section{Evaluation of 2 years operation}

Maintenance during 2 years of operation has been $1 \mathrm{~h}$ per week to manually check the unit and the logged values for concentrations before and after treatment. The hospital tests its emergency power system once a month. In connection to this the power to the AnescleanSW is broken. When it is manually started again, logged data are transferred to IVL for evaluation. Recalibration of the two $\mathrm{N}_{2} \mathrm{O}$ meters has been needed just twice a year. Including this, change of filter and some lubrication the average time spent on maintenance is estimated to $7-8 \mathrm{~h} /$ month. In spite of the planned stops, the availability of the system has been well over $99 \%$. The only non-intentional stop was that the fan stopped once in June 2006, without any obvious reason. Then the heater automatically turned off to protect the catalyst, and the alarm was shown in the central operating room.

The degradation of $\mathrm{N}_{2} \mathrm{O}$ over the Anesclean-SW has for each week after the optimisation tests (more than $21 / 2$ year) varied between $94 \%$ and $99 \%$. There are still after 3 years of operation no obvious signs of lower capacity of the catalyst. The amount of electric energy 
used has varied between 30 and $45 \mathrm{~kW} \mathrm{~h} / \mathrm{kg} \mathrm{N}_{2} \mathrm{O}$ split. The variation is mainly due to different amounts of $\mathrm{N}_{2} \mathrm{O}$ used. With constant temperature and air velocity the energy demand is also constant, since the energy gained in splitting of $\mathrm{N}_{2} \mathrm{O}$ in these concentrations has very little influence.

\section{Evaluation with LCA and LCC}

\subsection{LCA}

The environmental impacts caused by the treatment of $1 \mathrm{~kg}$ of $\mathrm{N}_{2} \mathrm{O}$ with the Anesclean-SW equipment were assessed by dividing the impacts from the manufacture, transport, use and disposal by the estimated amount of $\mathrm{N}_{2} \mathrm{O}$ fed to the Anesclean-SW during its service life (Almemark 2005). The environmental impacts from the manufacture of spare parts and accessories with a shorter service life than the apparatus itself were assessed in an analogous way.

The software KCL-ECO, version 3.1, was used for the calculations. Equipment life time was conservatively set to 10 years (except for details in fans, filters and other small parts), and the catalyst lifetime to 3 years (already shown to be realistic). Material composition of the delivered Anesclean-SW and conditions at Karolinska Huddinge hospital were used, including transport from Japan to Sweden. Recirculation of $75 \%$ of the active metal (rhodium) in the catalyst was assumed (according to Showa Denko). In this limited LCA generic data were used for manufacture of construction materials, supply of energy carriers and environmental impacts of transports construction material. The hospital uses just "Green electricity", from hydropower. Table 1 shows the result as maximum potential environmental impacts caused by $1 \mathrm{~kg}$ of $\mathrm{N}_{2} \mathrm{O}$ that is collected by the Anevac system. Figures for electricity totally from a coal power plant are also included as a worst case.

Table 1 Maximum potential environmental impact from $1 \mathrm{~kg} \mathrm{~N}_{2} \mathrm{O}$ from Anevac, with and without Anesclean-SW (A-SW)

\begin{tabular}{llccc}
\hline Impact category & Unit & Without Anesclean & With Anesclean & \\
\cline { 4 - 5 } & & & Hydro $^{\mathrm{a}}$ & Coal $^{\mathrm{a}}$ \\
\hline Resources, non-renewable & $\mathrm{kg}$ & 0 & 0.19 & 0.57 \\
Resources, renewable & $\mathrm{kg}$ & 0 & 0.04 & 0.0001 \\
Fossil energy carriers & $\mathrm{MJ}$ & 0 & 9.5 & 290 \\
Non-renewable energy c. (U) & $\mathrm{MJ}$ & 0 & 3 & 3 \\
Renewable energy carriers & $\mathrm{MJ}$ & 0 & 120 & 0.72 \\
Greenhouse effect (GWP) & $\mathrm{kg} \mathrm{CO}$ equiv. & 310 & 18 & 48 \\
Ozone depletion potential & $\mathrm{kg} \mathrm{CFC}-11$ equiv. & 0 & $8 \times 10^{-8}$ & $8 \times 10^{-8}$ \\
Acidification potential & $\mathrm{moles} \mathrm{H} \mathrm{H}^{+}$ & 0 & 2.37 & 3.2 \\
$\mathrm{O}_{3}$ creation potential & $\mathrm{kg}$ ethylene equiv. & 0 & 0.00032 & 0.003 \\
Eutrophication potential & $\mathrm{kg} \mathrm{oxygen} \mathrm{equiv.}$ & 0 & 0.046 & 0.13 \\
Toxic compounds & $\mathrm{kg}$ & 0 & $\mathrm{Many}$ & Many $^{-8}$ \\
Heavy metals & $\mathrm{kg}$ & 0 & $6.3 \times 10^{-5}$ & $6.3 \times 10^{-5}$ \\
Hazardous waste & $\mathrm{kg}$ & 0 & 0.0063 & 0.0063 \\
Waste & $\mathrm{kg}$ & 0 & 1.7 & 3.8 \\
\hline
\end{tabular}

${ }^{\text {a }}$ Electricity for the use of Anesclean-SW is totally from either hydropower or coal 
Table 2 Main causes of various potential environmental impacts by use of Anesclean-SW

\begin{tabular}{ll}
\hline Impact category & Main causes \\
\hline Renewable energy carriers & Hydroelectric power for Anesclean-SW operation \\
Greenhouse effect (GWP) & By-passed $\mathrm{N}_{2} \mathrm{O}$ \\
$\mathrm{O}_{3}$ creation potential & Production of nickel, electronics and plastics \\
Acidification potential & $\mathrm{SO}_{2}$ from production of new rhodium to catalyst \\
Eutrophication potential & Production of steel and transports Japan-Sweden \\
Toxic compounds & Mainly equipment: CO, HCl, HF, NO $\mathrm{N}_{X}$ dioxins, \\
& hydrocarbons and particles \\
Hazardous waste & Electronics \\
Waste & Mining waste \\
\hline
\end{tabular}

Table 2 shows the main causes of various potential environmental impacts for the studied case.

As always with evaluation of LCA different impact categories have to be compared. If you compare the five categories greenhouse effect, ozone depletion, acidification, photochemical ozone creation and eutrophication without and with Anesclean, the result is that the introduction of the Anesclean-SW very significantly reduces the greenhouse effect without causing unacceptable increases of other emissions, provided that all the impact categories are considered equally important. However, this comparison does not take into account that the use of Anesclean-SW also causes emissions of toxic compounds from the manufacture of the equipment. These emissions will hardly constitute an acute hazard at the locality where they take place. It is not possible to decide, however, whether or not the emissions of toxic compounds are acceptable in relation to the environmental benefits of a decreased greenhouse effect.

Possibilities to further improve the environmental profile of the Anesclean-SW are discussed later.

\section{$5.2 \mathrm{LCC}$}

A simplified LCC was also conducted (Kock 2005). Actual costs for purchase, transport and installation and customs, the same assumptions about lifetime as in LCA, 4\% interest, recovery of the catalyst and an electric energy price of $0.06 € / \mathrm{kW} \mathrm{h}$ were used. The cost $/ \mathrm{kg}$ $\mathrm{N}_{2} \mathrm{O}$ destroyed was calculated to almost $30 €$. Over $80 \%$ of the cost was from the original delivery. This makes the cost most sensitive for changes in lifetime and interest rate, while changes in energy price would not change the cost so much. The $30 € / \mathrm{kg} \mathrm{N}_{2} \mathrm{O}$ removed can for greenhouse effect be roughly compared to $0.1 € / \mathrm{kg} \mathrm{CO}_{2}$ removed. Possibilities to lower specific costs are discussed in next section.

\section{Possible improvements}

\subsection{Improved environmental profile}

The positive environmental effect of Anesclean-SW at Karolinska Huddinge hospital would increase if the production of the equipment had lower environmental impact, and if the specific energy needed was lower. This unit was a prototype, and it could probably be made with less total material and also less stainless steel. It could also be produced closer to the 
place of use. However, most important would be to treat more $\mathrm{N}_{2} \mathrm{O}$ per unit of time, and then also during the lifetime of the equipment. The splitting reaction is limited by the retention time in the catalyst, that is by the air flow rate. If the concentration of $\mathrm{N}_{2} \mathrm{O}$ in the air were higher, the positive environmental effect would increase proportionally.

An increased concentration would in the same way decrease the specific energy used. The decrease would be even more than proportional, since the splitting heat could also be used. With the existing gas collection system the concentration can possibly increase by lowering the base air flow or the negative pressure in the Anevac. However this would probably lead to more losses to the regular room ventilation that is not treated. This would also risk impairing the working environment for the personnel.

Showa Denko was not willing to let the $\mathrm{N}_{2} \mathrm{O}$ concentration in the air regulate the temperature in the catalyst, since the changes in concentration are much faster than the heating capacity. However, with the system to connect the Anevac air stream with Anesclean-SW, Fig. 2, there is another possibility. Since there are long periods when no $\mathrm{N}_{2} \mathrm{O}$ at all is used (approximately $50 \%$ of the time no mother is using $\mathrm{N}_{2} \mathrm{O}$ in any of the delivery rooms, it is just used during intense labour pains) there is a lot of air that can just as well be emitted directly to the atmosphere. The inlet $\mathrm{N}_{2} \mathrm{O}$ meter could give a signal to the inlet fan (4 in Fig. 1), so concentrations below 10 ppm reduced the air flow to $10-20 \%$ of the normal. The level should be determined so the catalyst is not overheated when the flow rate decreases, and the temperature drop is not too big when the air flow increases to normal. This could decrease the energy need by up to $40 \%$, or down to about $20-25 \mathrm{~kW} \mathrm{h/} \mathrm{kg} \mathrm{N} \mathrm{N}_{2} \mathrm{O}$ destroyed. A system like this will be tested.

\subsection{Improved economy}

Even with energy prices twice as high as in 2005 the above mentioned energy savings would not mean more than $5 \%$ lower total or specific cost in this specific case. Since more than $80 \%$ of the cost now is from capital costs and taxes, this is where changes would have an impact. Almost $20 \%$ of the total investment cost was taxes. This is about $15 \%$ of the total cost. Production of Anesclean-SW in longer series and a little less exclusive housing could also contribute to decrease the specific cost in a case like Karolinska Huddinge hospital to about $18 € / \mathrm{kg} \mathrm{N} \mathrm{N}_{2} \mathrm{O}$ removed, or $0.06 € / \mathrm{kg} \mathrm{CO}_{2}$ equivalent. This is still much higher than the current price for $\mathrm{CO}_{2}$ emission permits, but it is lower than some actions to decrease $\mathrm{CO}_{2}$-emissions. Most important to get a lower specific cost is a higher concentration of $\mathrm{N}_{2} \mathrm{O}$ in the treated air.

\subsection{Improved collection of $\mathrm{N}_{2} \mathrm{O}$}

In the specific case at Karolinska Huddinge hospital the positive environmental effect would increase and the specific cost decrease if the masks could collect more of the $\mathrm{N}_{2} \mathrm{O}$ in a more concentrated stream. However, there is an opposition against the complementing chin mask among midwives and mothers. Without this chin mask all $\mathrm{N}_{2} \mathrm{O}$ that is exhaled after the mother has removed the double mask is lost to the regular ventilation system. As it is now, without the chin mask, about $70 \%$ of the used $\mathrm{N}_{2} \mathrm{O}$ is collected by the Anevac system. Different ways to solve this are tested.

The average concentration of $\mathrm{N}_{2} \mathrm{O}$ in the regular ventilation system is about $50 \mathrm{ppm}$, and treatment in a system like Anesclean-SW would be very expensive. It is possible to concentrate the $\mathrm{N}_{2} \mathrm{O}$ in this air stream by sorption, and then desorb it in higher concentration 
for destruction. Such systems are investigated, and necessary to reach the new set goal by SCC to decrease $\mathrm{N}_{2} \mathrm{O}$ emissions by $75 \%$ (with unchanged use of $\mathrm{N}_{2} \mathrm{O}$ ).

Acknowledgement This investigation and installation was initiated and financed by the Stockholm County Council, with economical contribution from KLIMP, the Swedish EPA climate investment programme.

Open Access This article is distributed under the terms of the Creative Commons Attribution Noncommercial License which permits any noncommercial use, distribution, and reproduction in any medium, provided the original author(s) and source are credited.

\section{References}

Almemark M (2005) LCA of a method to decompose laughing gas. Internal report to Stockholm County Council

Arenas-Alatorre J, Gómez-Cortés A, Avalos-Borja M, Díaz G (2005) Surface properties of $\mathrm{Ni}-\mathrm{Pt} / \mathrm{SiO}_{2}$ catalyst for $\mathrm{N}_{2} \mathrm{O}$ decomposition and reduction by $\mathrm{H}_{2}$. J Phys Chem B 109:2371-2376

Burch R, Breen JP, Meunier FC (2002) A review of the selective reduction of $\mathrm{NO}_{X}$ with hydrocarbons under lean-burn conditions with non-zeolitic oxide and platinum group metal catalysts. Appl Catalysis B: Environmental 39(4):283-303

Chaki T, Arai T, Ebina M, Shimokawabe M (2003) Catalytic reduction of $\mathrm{N}_{2} \mathrm{O}$ by $\mathrm{C}_{2} \mathrm{H}_{4}$ over Fe-ZSM5: formation and nature of carbonaceous deposits and influence of addition of $\mathrm{O}_{2}$. J Catalysis 218 (1):220-226

Ek M, Tjus K, Rahmberg M, Brundin S (2005) Utvärdering av lustgasdestruktionen vid Huddinge sjukhus (Evaluation of laughing gas destruction at Huddinge hospital). Internal report to Stockholm County Council

Kai T, Kanmura Y, Takahashi S, Atobe H, Hotta M (2002) Development and utilization of a system for treating waste anesthetic gases, ASA abstract. Anesthesiology 96:A574

Kock E (2005) LCC för lustgasdestruktion (LCC for laughing gas destruction). Internal report to Stockholm County Council

Liu Z, Amiridis MD, Chen Y (2005) Characterisation of CuO supported on tetragonal $\mathrm{ZrO}_{2}$ catalysts for $\mathrm{N}_{2} \mathrm{O}$ decomposition to $\mathrm{N}_{2}$. J Phys Chem B 109:1251-1255

Olofsson C, Irestedt L (1998) Traditional analgesic agents: are parenteral narcotics passé and do inhalational agents still have a place in labour? Baillieres Clin Obstet Gynaecol 12(3):409-421

Zhu ZH, Lu GQ, Yang RT (2000) New insights into alkali-catalyzed gasification reactions of carbon: comparison of $\mathrm{N}_{2} \mathrm{O}$ reduction with carbon over $\mathrm{Na}$ and $\mathrm{K}$ catalysts. J Catalysis 192:77-87 